interesting study. For more information on IOM please visit the Dentaid website http://www.dentaid.org/resources /iommaterials.

\section{J. Gollings}

Poole

DOI: 10.1038/sj.bdj.2011.433

\section{REMAINS OF THE DAY}

Sir, of course, as always and quite rightly, you seek to provoke us (For want of a nail; BDJ 2011; 210: 245) and I wish to accept this particular challenge.

The key points you make are, incontrovertibly, that there is a massive decline in caries and therefore a concomitant increase in the number of people having functional natural dentitions in the UK. The second 'conflicting' trend you introduce is that there is a corresponding increase in the number of dentists and also dental hygienists and therapists in the UK, arguing that these dental professionals will become increasingly "underemployed and at worst unemployed'.

My opposing argument is that this is false reasoning because you did not take into account the fact that the people with functional natural dentitions are living longer. They also wish to keep their functional natural dentition because they are better educated and they have greater disposable incomes to spend on dentistry. They perceive that keeping the natural dentition maintains the quality of life. Because of the increasing importance of the media and visual communications they also perceive that this quality of life may be improved by changing the aesthetics of these ageing teeth with whitening, cosmetic treatment and adult orthodontics. In addition, with the increasing availability of implants the loss of a functional tooth is now no longer regarded as irreversible, at any age.

To carry out these complex procedures, periodontal status has to be improved and maintained. The Adult Dental Health Survey 2009 reports: 'Periodontal disease remains common at a low level although overall there has been a reduction in mild disease associated, perhaps, with a general increase in cleanliness. However, there has been a slight increase in the prevalence of more severe disease and the impacts of severe disease are concentrated in a relatively small proportion of the population'. I would suspect that as more teeth are kept for longer, with the reduction of caries and increased longevity, the incidence of periodontal disease in older people will actually increase. Not only that, but as the recommendations for early diagnosis and treatment become more stringent, the need for periodontal treatment will further increase.

Neither did you report on the 'new' disease of tooth surface loss which has replaced caries in younger patients as the biggest time consuming challenge for many practitioners. We also need to consider preventive strategies in older patients for the treatment of dry mouths and root caries. In addition, the clinical output of each individual dental professional will probably be reduced in future by the time consuming needs of clinical governance, the Care Quality Commission and reaccreditation.

Finally, the main increase in numbers of dentists in the UK is probably nothing to do with the UK government's increase in training places, but is more to do with market forces and the influx of dentists from the European Union and is therefore beyond the control of planners. I conclude that demographic change, increased dental awareness and the need for preventive strategies will increase rather than reduce the demand for treatment in primary dental care.

M. Austin

Hove

DOI: 10.1038/sj.bdj.2011.434

\section{REFRESHINGLY REALISTIC}

Sir, I note from the letter of J. Truter (Shame on the MPs; BDJ 2011; 210: 97) that the response of their MP was a standard letter. This may well be a result of the use of a standard postcard.

My experience with my MP was very different as she entered into a personalised exchange of emails. She was keen to learn more of my opinions and was, at all times, refreshingly realistic as to what could be achieved. At one stage my concerns, along with those of other constituents, were raised with Lord Howe the health minister who provided the assurance that $\mathrm{CQC}$ regulation is intended to be 'light touch'.
It is too easy to generalise in these circumstances; there are open minds in government.

\section{P. Davies}

By email

DOI: 10.1038/sj.bdj.2011.435

\section{SPLINTS AS PLACEBOS}

Sir, I refer to the letter from J. M. Zakrzewska on behalf of the facial pain unit Eastman Dental Hospital. ${ }^{1}$

A multi-disciplinary approach is essential in understanding and treating 'TMD'.

Splints or bite raising appliances cannot be considered as 'placebos' as they, by definition, have a definite physiological effect. They should therefore be considered as 'pacifiers or comforters'.

In my experience, inserting a longitudinal cut length of a cotton wool roll of equal thickness on the lower posterior teeth of each side of the dental arch and guiding cushioned closure will reduce the tension in the oral, mandibular and swallowing musculature, by removing the displacing premature occluding contacts.

This simple procedure in itself is very informative for the patient and dentist.

C. G. W. Wilks Billesdon

1. Zakrzewska J M. Consistently amazed. Br Dent J 2011; 2011: 248

DOI: 10.1038/sj.bdj.2011.436

\section{REFRESHING DISCUSSION}

Sir, I congratulate Brocklehurst and Tickle (BDJ 2011; 210: 303-308) for focusing on the business aspect of delivering dental care in the primary care setting, by using skill mix.

We are all aware of our duty to patients and improving oral health outcomes. However, primary dental care is foremost a 'business' and with a significant risk borne by many of the practitioners reading this journal. It is refreshing to see an open discussion and exploration of the profitability in using dental therapists, dental hygienists and/or extended duty dental nurses. Naturally, a simplified business model has been used in the paper and every practice will need to look at their own individual circumstances when considering skill mix. Over the last few years, there has been a particular drive by PCTs in implementing 
skill mix in general dental practice, under the aspirations of better oral healthcare for patients. However, based on personal experience, many policymakers are ignorant or naive to the business of dentistry (the word 'profit' seems to be a taboo!), and are often reluctant to discuss these issues. I hope articles like this and further discussions are taken into consideration in future NHS contract developments and dental workforce planning in the UK.

B. Gupta

Wolverhampton

DOI: 10.1038/sj.bdj.2011.437

\section{QIPP, OR JUST Q?}

Sir, I congratulate Brocklehurst et al. on their informative paper, QIPP: cutting budgets or working smarter? ${ }^{\text {I }}$ imagine much of the profession will be dismayed at the approach of another acronym, so I shall try to be of assistance. I agree that Lord Darzi's NHS Next Stage Review ${ }^{2}$ points out aspects of quality that include effectiveness, patient experience and patient safety. Problems arise, however, when we move beyond the 'Q' in QIPP. Innovation has been variously defined, but my view is that innovation includes devices, systems, policies, programmes, products or services that are adopted/ adapted from other organisations, as well as those that are invented by the organisation itself; this approach has been supported by academics in the subject. ${ }^{3,4}$ Lord Darzi's report also emphasises the importance of innovation. ${ }^{2}$ It is my view that continual scoping for adoption and subsequent implementation of good innovation is essential to promote quality. We can therefore lose the 'I' from QIPP as it can be included in quality. Lord Darzi's ${ }^{2}$ report also emphasises the important role that prevention has to play in a quality service. We can therefore now lose the first 'P' as now this can also be included in quality. This leaves us with productivity. This is a measure of output. However, it is felt that it is much better to assess the dynamics of patient care in terms of effectiveness, ${ }^{5}$ which takes into account outcomes. The last 'P', for productivity, can therefore be dropped as inappropriate and it cannot be replaced by ' $E$ ' for effectiveness as this is included in quality. We are therefore just left with 'Q'. But in many respects we are still waiting for the 'A'.

\section{P. Kelly}

Weymouth

1. Brocklehurst $P$, Jones $C$, Tickle M. QIPP: cutting budgets or working smarter? Br Dent J 2011 210: 369-373.

2. Department of Health. High quality care for all. NHS Next Stage Review Final Report. Cm 7432. Norwich: TSO, 2008.

3. Damanpour F. Organizational innovation: a metaanalysis of effects of determinants and moderators. Acad Manage J 1991; 34: 555-590.

4. Mohr L B. Determinants of innovation in organizations. Am Polit Sci Rev 1969; 63: 111-126.

5. Donabedian A. An introduction to quality assurance in healthcare. pp 6-10. New York: Oxford University Press, 2003.

DOI: 10.1038/sj.bdj.2011.438

\section{DAYLIGHT ROBBERY}

Sir, these were not my words but those of my experienced and longstanding nurse when she heard what one dentist was going to charge to remove one intraoral suture.

I saw a patient under the NHS and the band 2 treatment I provided included the exam, scaling, X-rays, a class II (MO) amalgam and a surgical extraction of the upper right 7.

The treatment went without incident but as the patient lived some 20 miles away, I suggested they might find a local dentist who should remove the suture without charge.

The NHS practice she phoned couldn't see her for two weeks (maximum 60 seconds surgery time?) and a private practice wanted $£ 60$, yes sixty pounds to remove one suture! The patient returned to me.

I received a little over that amount for carrying out the band 2 treatment and it reminds me of sometimes the huge gulf in the cost of private and NHS care and yet if unfortunately a course of treatment came under the scrutiny of the courts, I would be expected to have provided the same standard of treatment whether I had done, for example, a molar endo and received around £70 to include other treatment, or it had been done privately at a cost of $£ 650$ which I know is a going rate of a specialist endodontic practice in my area. I wonder sometimes why I dare to provide NHS care but I do and have done very happily for over 34 years.

\section{P. Williams}

Lowestoft

DOI: 10.1038/sj.bdj.2011.439

\section{COUNCIL APPOINTMENTS}

Sir, my understanding of the current situation is that the GDC Council is appointed by the Appointments Commission, a Non-Departmental Public Body (NDPB, also known as a quango). Registrants no longer have the right to vote on who sits on the Council. I also understand that the Appointments Commission is due to be abolished. ${ }^{1}$ This was announced as part of the Government's cull on quangos in October 2010. In light of this, do any well informed colleagues know how the GDC Council will be appointed in the future? Will we be going back to the 'old' system?

R. Vasant London

1. Public bodies reform - proposals for change. http://www.direct.gov.uk/prod_consum_dg/ groups/dg_digitalassets/@dg/@en/documents/ digitalasset/dg_191543.pdf

DOI: 10.1038/sj.bdj.2011.440

\section{OSA AND MAD}

Sir, obstructive sleep apnoea (OSA) affects $1-2 \%$ of the population and occurs most often in overweight middle-aged men. OSA may result in excessive sleepiness, impaired intellectual performance, an increased risk of accidents and an impaired quality of life. ${ }^{1}$ Management of OSA can be divided into Continuous Positive Airway Pressure (CPAP) therapy, surgery and oral appliance therapy.

The use of Oral appliances, such as the Mandibular Advancement Device (MAD) has been shown to significantly improve nocturnal respiratory function and sleep quality in patients with OSA, even in patients with severe OSA. ${ }^{2}$ Thus MAD can be used as an alternative treatment modality regardless of severity because it is non-invasive, easy to manufacture and clinically effective. However, when considering the use of a MAD, the patient's dental health must be fully assessed. Insufficient teeth, pre-existing periodontal disease and TMJ pathology all have been shown contraindications to the use of MAD. ${ }^{3}$

We present a patient that developed mobility of his upper and lower anterior teeth following one week use of a MAD for treatment of OSA, despite the patient not having any clinical evidence of pre-existing periodontal disease 